\title{
ESPAÑA Y POLONIA: LOS PRIMEROS CRUCES DE CAMINOS EN LA HISTORIA Y EN LA LITERATURA
}

\author{
Fernando PRESA GONZÁLEZ
}

Universidad Complutense de Madrid

Al iniciar estas letras, quiero expresar a mi querido amigo y admirado colega, el Prof. Dr. D. José Enrique Martínez Fernández, mi afecto y gratitud personal por treinta años de amistad y, de ellos, más de veinte de intensa y magnánima colaboración científica con la Filología Eslava de la Universidad Complutense de Madrid.

Gracias, José Enrique, por ser siempre un amigo noble, un colega generoso y un maestro admirable.

E spaña y Polonia, a pesar de ser países ubicados en los extremos del continente europeo, han tenido, en no pocas ocasiones, una historia compartida. Compartida en sus orígenes culturales y compartida en los destinos políticos y religiosos de la vieja Europa. Polonia, aunque perteneciente lingüísticamente al ámbito eslavo, siempre ha encontrado sus referencias culturales e ideológicas al oeste de sus fronteras; y dentro de esas referencias, lo español siempre fue un elemento importante en la conformación de la cultura polaca y en su desarrollo ulterior.

El acontecimiento histórico más memorable de entre los primeros que tuvieron lugar entre España y Polonia es el matrimonio en segundas nupcias del Rey de Castilla, León y Galicia Alfonso VII ‘el Emperador' (reinado: 1126-1157) (viudo de Berenguela de Barcelona) con la princesa Rica de Polonia (Ryska), hija de Ladislado II 'el Desterrado', de la dinastía de los Piast. Es de suponer que este acontecimiento abriera las puertas a los primeros contactos culturales y que en uno y otro país se hablara, no sin una buena dosis de fantasía, de sus realidades.

Los contactos se incrementan especialmente a partir del siglo $\mathrm{XV}$, en cuyas peregrinaciones a Santiago desde toda Europa se encuentra un buen número de polacos, que a su regreso dejan testimonios escritos de sus experiencias en España. Más aún se incrementan las relaciones durante el reinado de los Reyes Católicos, lograda la unidad de España y recién descubierta América, lo que sitúa a los españoles en un lugar de poder y privilegio político en Europa, y que, consecuentemente, despierta en todo el continente un gran interés por el país, su gente y su lengua. Polonia, que contaba con un importante mercado marítimo internacional a través de su puerto báltico de Gdańsk, intensifica 
sus relaciones comerciales con los mercados españoles, al tiempo que aumenta sus relaciones diplomáticas con España.

La actividad libresca se va intensificando a medida que pasan los años. En 1490 llega Stanislaus Polonus ( $†$ h. 1514) a Sevilla, donde se establece como impresor y lleva a cabo una extraordinaria labor de difusión de textos impresos (más de ochenta impresos castellanos, latinos y catalanes), relativos al Descubrimiento de América, obras religiosas, científicas y literarias, las cuales pronto llegaron también a Polonia.

A tierras polacas llegaron también libros españoles y noticias sobre España entre los enseres de los judíos expulsados en 1492 y que buscaron refugio también en tierras eslavas.

De todos los embajadores que en aquellos tiempos visitaron España hay que destacar a Jan Dantyszek o Juan Dantisco (1485-1548), embajador polaco del Rey Segismundo I 'el Viejo' en España. Este polaco de Gdańsk, tras estudiar en la Universidad de Cracovia, se inició en la carrera diplomática. Entre 1518 y 1524 fue enviado a España en tres ocasiones en misión diplomática ante Carlos I. La tercera de ellas, en 1524, se prolongó hasta 1532, por lo que residió casi permanentemente en España durante ocho años. En sus creaciones poéticas, muy populares en aquella época, cultivó epigramas, epitalamios, entre los que cabe destacar el dedicado a la reina Bona y titulado Ephitalamion reginae Bonae (1518), poemas políticos, como el titulado De nostrorum temporum calamitatibus silva (1530), epitafios, panegíricos y otras composiciones de carácter didáctico, moral y religioso, en las que se encuentran numerosas referencias españolas e influencias de la cultura hispánica. Sabemos que Dantisco envió y transportó a Polonia un buen número de libros procedentes de la Península Ibérica durante sus viajes entre España y Polonia.

Aún más intensamente realizó esta labor de adquisición y traslado a Polonia de libros españoles el obispo de Płock, Piotr Dunin Wolski, quien enviado por el Rey polaco Segismundo II Augusto en misión diplomática ante Felipe II entre 1561 y 1573, reunió y llevó a tierras polacas más de 300 obras de la mejor literatura española hasta el siglo XVI, conjunto que se conoce como la 'Bibliotheca Volsciana', integrada en los fondos de la Biblioteca Jaguelónica de Cracovia. La gran mayoría de los libros españoles que llegaban a Polonia procedían de los acopios particulares que en sus viajes realizaban los polacos llegados a España. Se sabe que algunos de ellos terminaban en el mercado del libro, aunque no era lo corriente, tratándose en estos casos, normalmente, de textos latinos. A partir de la Edad Media encontramos en las colecciones polacas de libros españoles trabajos latinos de juristas, teólogos y cronistas, principalmente, así como las obras de San Isidoro de Sevilla, libros varios de astronomía y medicina.

Que la Akademia Krakowska o Universidad de Cracovia, fundada en 1364, lo que le permite ostentar el título de una de las más antiguas de Europa, era centro europeo de interés científico y cultural lo prueba el hecho de que hasta ella llegaran juristas españoles, como el sevillano Garsías Quadros, quien impartió docencia en Leyes entre 1510 y 1517, y el aragonés, natural de Alcañíz, Pedro Ruiz de Moros, conocido en Polonia como Piotr Roizjusz (h.1506-1571), también docente en la Universidad de Cracovia y miembro de la corte de Segismundo II 'el Augusto', a quien el poeta 
Mikołaj Rej (1505-1569) dedicaría un epigrama en su Jardín zoológico en que se describen las figuras, cualidades y costumbres de diversas clases de hombres, animales y pájaros (Zwierzyniec, w którym rozmaitych stanów ludzi, zwierząt $i$ ptaków kształty, przypadki i obyczaje sa właśnie wypisane) (Cracovia, 1562). También el maestro Jan Kochanowski (1530-1584) le dedicaría una de sus más famosas composiciones en el volumen Bagatelas (Fraszki) (1584).

El avance del protestantismo en toda Europa dio lugar a la ejecución de la Contrarreforma por parte de la Iglesia católica. Al luteranismo se añadían nuevos conflictos religiosos: el calvinismo, el cisma provocado por Enrique VIII de Inglaterra (1509-1547) y, más tarde, el anglicanismo instaurado por Isabel I (1558-1603). El Papa Paulo III (pontificado: 1534-1549) convoca en 1545 el Concilio de Trento, que durará hasta 1563, con el doble propósito de restablecer la disciplina de la Iglesia y aclarar el dogma católico. Si bien es cierto que el clero católico polaco no se manifestó en un principio partidario de la Contrarreforma, la presencia de la Compañía de Jesús, fundada por el caballero español Ignacio de Loyola, aprobada por Paulo III en 1540 y concebida como un ejército en marcha en defensa de la religión católica, contribuyó decisivamente, desde que el cardenal Stanisław Hozjusz (15041579) la introdujo en Polonia en 1564, a la progresiva pérdida de influencia del protestantismo y a la revitalización del catolicismo en tierras polacas. El Índice tridentino de libros prohibidos de 1564 abrió el camino a la Compañía de Jesús para que llevara a la hoguera miles de libros en 1581, en Vilna. La censura eclesiástica inspeccionó numerosas imprentas y librerías y confiscó todos los libros considerados como peligrosos para la religión católica, entre los que se encontraban las obras del polaco Nicolás Copérnico (Mikołaj Kopernik) (1473-1543). Pero los Jesuitas habían ya realizado una importante labor de infiltración del pensamiento de los ascetas y místicos españoles, lo que se refleja claramente en la actividad teatral escolar. La Compañía de Jesús, consciente del poder didáctico del teatro, mantuvo desde su implantación en Polonia un vivo interés por el desarrollo de éste en sus colegios. Vilna (1570), Poznań (1573), Lublin (1594) y otras muchas ciudades en las que los jesuitas establecieron sus centros de enseñanza armonizaron la formación teórica con la actividad teatral de los escolares. Junto a ellos, las Escuelas Pías y la congregación de los Teatinos, en Polonia desde 1642 y 1687 respectivamente, fueron los principales protagonistas del desarrollo del teatro escolar. En muchos de sus centros docentes, como los de Toruń, Elbląg y Gdańsk, había con frecuencia representaciones teatrales, llevadas a cabo por los propios escolares. De la importancia que daban al teatro da prueba el hecho de que en 1687 los jesuitas de Varsovia destinaran un edificio exclusivamente a la actividad teatral. Su cometido era claro: difundir el ideario de la orden y de la Iglesia contrarreformista y conmover a los estudiantes hacia el respeto y la práctica de la doctrina moral católica. La lucha contra los herejes, dramatizada mediante personajes alegóricos como 'la virtud cristiana' o 'la verdadera fe', fue el tema más recurrido por los autores, que escribían en latín y en esta misma lengua veían representadas sus obras. El culto a la Virgen María, a la Santísima Trinidad, a los santos de la Compañía de Jesús, San Ignacio de Loyola y San Estanislao de Kostka, eran motivos frecuentes en las representaciones. La formación del espíritu del caballero cristiano también era cometido de este teatro escolar, que, frecuentemente, recurría a modelos de la historia de España y de la orden de los jesuitas. 
Otro de los elementos tradicionalmente señalados como vía de penetración de 'lo español' en Polonia es la moda procedente de España, a cuya difusión contribuyó el casamiento de la princesa milanesa Bona Sforza de Bari con el Rey Segismundo I ‘el Viejo’, elevada al trono de Polonia en 1518 en virtud de este matrimonio. Esta generosa mecenas, a la que acompañaron hasta la corte de Cracovia no sólo embajadas y altos dignatarios civiles y eclesiásticos, sino también prestigiosos maestros de las bellas artes y las letras italianas, difundió en los salones de los palacios polacos los gustos españoles, en aquellos tiempos predominantes en tierras italianas. Esto se prolongaría aún durante el reinado de Segismundo III (1587-1632). La moda española arrastró también «lo español» en toda su dimensión como elemento al uso. Y así, el conocimiento de la lengua española está indicado como requisito necesario que debe presentar un consejero real en obras didácticas como El cortesano polaco (Dworzanin polski) (1566) de Lukasz Górnicki (1527-1603) —refundición de la obra de Baltasar de Castiglioni- - E El espejo u obra en la que cada estamento puede fácilmente contemplar sus cuestiones como en un espejo (Zwierciadto albo ksztatt, w którym każdy stan snadnie się może swym sprawom jako we zwierciadle przypatrzyć) (1568) de Mikołaj Rej. También se publicaron diccionarios, como el Vocabulario de las dos lenguas, Toscana y Castellana (1576), obra de De las Casas.

Ya en el siglo XVII, el establecimiento en Polonia, en el año 1605, por parte del Rey Segismundo III, de la primera fundación de la Orden de los Carmelitas Descalzos, trae como consecuencia la inmediata difusión de las obras de los místicos españoles, alcanzando gran popularidad Santa Teresa de Jesús y San Juan de la Cruz. El interés por España es ya en este siglo tan intenso que cuando aparece en 1661 la primera publicación periódica polaca, El Mercurio polaco (Merkuriusz polski), inicialmente en Cracovia y después en Varsovia, gaceta en la que se ofrecía al lector información no sólo sobre Polonia, sino también acerca de la situación política de los diferentes países europeos, el desarrollo económico y comercial, las tragedias naturales ocurridas, las epidemias que amenazaban y otras muchas noticias de interés general, entre las noticias más destacadas y abundantes se encuentra la información relativa a la guerra entre España y Portugal.

Las obras de los autores españoles se publicaban habitualmente en forma de traducciones o reelaboraciones, siendo las pertenecientes a la corriente ascético-mística las de mayor presencia en Polonia en estos siglos. En Vilna se publica la versión latina original de Exercitia spiritualia (1583) de San Ignacio de Loyola, edición a la que siguen traducciones de obras de carácter moralista como la Instrucción cristiana para los niños (Mleko duchowne) (1566) de Juan de Valdés (1499-1541). Extraordinariamente se difundió en Polonia la obra del dominico Fray Luis de Granada (1504-1588), cuya Guía de pecadores (1556) contó con dos versiones traducidas al polaco: una de S. Warszewicki, titulada Przewodnik grzesznych ludzi (1567), realizada a partir de la primera versión española y puesta en duda por la Inquisición; y una segunda versión polaca realizada por A. Ch. Załuski, Przewodnik grzeszników (1687), elaborada según la segunda edición corregida de la obra. Del Libro de la oración y meditación (1554) se ocuparon también Warszewicki, quien tradujo un fragmento y lo publicó como texto independiente en polaco bajo el título Zwierciadło człowieka cheścijańskiego (1577), y $\mathrm{H}$. Drzewicki, traductor y reelaborador de la misma obra de Fray Luis de Granada a la que tituló en polaco 
España y Polonia: los primeros cruces de caminos en la historia y en la literatura

Exercycya albo zabawy duchowne (1688). A J. Wuchaliusz se debe la versión polaca hecha desde el italiano del Memorial de la vida cristiana (1561), que en polaco resultó ser Żywot Pana Jezusów (1592), y a Antonin de Przemyśl se debe la traducción del Rosario (Różańiec) (1583) de Fray Luis de Granada (1584).

S. Nuceryn fue el introductor y traductor al polaco de la obra de Santa Teresa de Jesús. A él se deben las primeras versiones del Libro de las fundaciones (1588), en polaco O Fundacjach (1632), Camino de perfección (1583), en polaco Droga do doskonałości (1625) y Castillo interior o tratado de las moradas (1588), en polaco Zamek wewnętrzny abo gmachy dusze ludzkiej (1633), obras que pronto ejercieron su influencia en poetas polacos como Elżbieta Drużbacka (h.1698-1765), autora de un Compendio de ritmos espirituales, panegíricos, morales y mundanos (Zbiór rytmów duchownych, panegirycznych, moralnych i światowych) (1752).

San Juan de la Cruz, traducido primero al latín por el carmelita polaco A. Brzechffa en el volumen Joannes a Cruce. Opera mystica (1639), no fue traducido al polaco hasta 1766 , año en que se publica una selección de textos bajo el título Rozmowy zbawienne.

Otro amplio grupo de obras españolas traducidas al polaco lo constituyen los trabajos de carácter parenético de pensadores españoles. Los escritos pedagógicos de Juan Luis Vives (1492-1540), encuentran eco, principalmente, en la obra de Andrzej Frycz Modrzewski Commentatorium de Republica emendanda libri quinque. Liber primus de moribus, secundus de legibus, tertius de bello, quartus de ecclesia, quintus de scholae. Los tres primeros libros se publicaron en Cracovia en 1551. La censura no permitió que los dos últimos salieran a la luz. Tuvo que esperar a 1554 para ver su obra completa editada en Basilea. En 1599 Cyprian Bazylik la tradujo al polaco ( $O$ poprawie Rzeczypospolitej) y a partir de ese año se realizaron varias traducciones, entre ellas al alemán, al francés, al ruso y al español. Las ideas que defiende en la obra no se distancian mucho de las de Erasmo de Rotterdam. Así, parte del principio de que la bondad es algo inherente a la naturaleza humana, la cual se perfecciona mediante actos de fe y generosidad. Lejos de una presentación utópica de la organización estatal, propone reformas concretas para el mejoramiento de la República.

Los manuales escolares que constituían la base de la educación lingüística y retórica de los colegiales polacos fueron llevados hasta Polonia desde la Península Ibérica por las órdenes religiosas allí establecidas (especialmente las escuelas de jesuitas), algunos de los cuales también se tradujeron al polaco. Es el caso de De institutione gramaticae (1572) del portugués M. Alvar, cuya edición polaca apareció en 1577, De arte rhetorica libri tres (1560) del español C. Suárez y Exercitationes linguae latinae de Juan Luis Vives, obra publicada en 1594 en versión polaca, realizada por M. Volckmar.

El Libro áureo de Marco Aurelio, publicado anónimo en Sevilla en 1528, fue agregado al Libro llamado relox de príncipes (Valladolid, 1529), ambos de Fray Antonio de Guevara (1480-1545) y editados en Polonia, primero en latín en 1615 (Horologium principum seu de vita Marci Aurelli) y más tarde en polaco, en versión de F. Roszkowski, en 1751 y bajo el título Zegar monarchów.

La primera parte de la obra de Quevedo (1580-1645) Política de Dios, Gobierno de Cristo (1626) fue traducida muy pronto al polaco, en 1633, con el título Polityka Boża i Rządy Chrystusowe, bajo el 
pseudónimo de 'Janusz Iberski z Andaluzji'. De Baltasar Gracián (1601-1658) se leía en Polonia su Oráculo manual y arte de prudencia sacada de los aforismos que se discurren en las obras de Lorenzo Gracián (1647), que contó con traducciones fragmentarias de J. Daneykowicz Ostrowski (Swady) (1747) y A. Brodowski (Maksymy) (1764), entre otros. También El discreto (1646) de Gracián fue conocido en Polonia, primero en francés y más tarde en traducción polaca realizada por P. Brzostowski, titulada Człowiek uniwersalny (1762).

Menor es el número de traducciones o refundiciones de autores españoles en los géneros de la novela y el teatro, los cuales llegaban hasta Polonia en traducciones italianas. Tal es el caso de la Bella y lastimosa historia de Equanius, rey escocés (Historia bardzo piękna i żałosna o Ekwanusie, królu szkockim) (1578) de Bartłomiej Paprocki (h.1543-1614), elaborada a partir de la versión italiana de la novela de Juan de Flores Historia del Grisel y Mirabella, con la disputa de Torrellas y Brançayda (editada en Lérida alrededor de 1495) y La bella Pascualina, cambiada recientemente del ropaje español al polaco (Nadobna Paskwalina z hiszpańskiego świeżo w polski przemieniona ubiór) (1655), de Samuel Twardowski, inspirada en Los siete libros de la Diana (1558/1559) de Jorge de Montemayor (h.1520-1561). Twardowski ubica la acción de su obra en la Lisboa del siglo XVI, donde Paskwalina y Wenera compiten por el laurel de la belleza. Wenera, enfrentada a Paskwalina, ruega a Cupido que dispare una flecha de amor al corazón de su rival, la cual queda prendada por el joven Oliwer, el cual, sin embargo, ama a su novia Kornelia. Paskwalina, que siente un amor no correspondido, vaga por extraños y lejanos lugares, donde se va encontrado con diferentes personajes mitológicos y alegóricos, como Apolo, Kupido, Diana y Juno. Y no pudiendo hacer realidad su amor, se hace monja, en contra de los designios de Cupido, el cual, al no lograr tampoco su propósito, decide morir colgado de un arrayán.

Las nuevas formas, italianas y españolas, sobre todo el soneto, llegan a la literatura polaca durante la transición del Renacimiento al Barroco, que en Polonia se encargan de adaptar y fijar, principalmente, Mikołaj Sęp-Szarzyńki (1550-1581), Sebastian Fabian Klonowic (1545-1602) y Szymon Szymonowic (1558-1629).

Siguiendo los modelos de la lírica italiana, lo que se conoce como el «petrarquismo espiritual», y también de la mística española, publicó Sebastian Grabowiecki (h.1543-1607) Rimas espirituales (Setnik rytmów duchownych) (1590), dos tomos que albergan más de doscientas composiciones poéticas en cuarenta y ocho tipos distintos de modelos estróficos, entre las que se encuentran numerosos sonetos con nuevas combinaciones de rima. Grabowiecki escribe una poesía metafísica en la que se manifiesta convencido de que el destino del hombre está perfectamente preestablecido por Dios, por lo que propugna una vida contemplativa, lejos de los bienes terrenales, que lleve al hombre a la superación de las debilidades del mundo y de la carne, así como del pecado.

No son muchos los datos que se tienen de la corta vida de Mikołaj Sęp-Szarzyński (h.15501581), si bien se supone que tuvo que provenir de una familia protestante porque realizó estudios en la Universidad luterana de Wittenberge, y que más tarde, tanto su padre como él, se convirtieron al catolicismo. No está documentada su estancia en Italia, aunque sí su buen conocimiento de la lengua 
italiana, por lo que es más que probable que residiera allí durante algún tiempo, e incluso que realizara estudios. También resulta muy probable que fuera en Italia donde leyera por primera vez a los ascetas y místicos españoles, aunque lo que sabemos con certeza es que conoció las traducciones al polaco de las obras de Fray Luis de Granada (1504-1588) Guía de pecadores (1556) y Memorial de la vida cristiana (1561), realizadas del italiano, como ya dijimos, por el jesuita Stanisław Warszewicki (15301591) con el título Przewodnik grzesznych ludzi la primera, cuya buena acogida hizo que tuviera tres ediciones relativamente seguidas en 1567, 1570 y 1579, y Zwierciadło człowieka chrześcijańskiego la segunda, publicada en 1577. Asimismo, tuvo que tener una importante influencia en su formación como poeta religioso — Sęp-Szarzyński es, prácticamente, el único místico polaco — su amistad con el dominico Antonin de Przemyśl, también traductor del Rosario (Różańca, 1583) de Fray Luis de Granada.

Las primeras creaciones poéticas Kasper Twardowski (h.1592-h.1641) no pertenecen a la poesía metafísica, aunque terminara siendo un importante poeta religioso. Sus poemas primeros se adscriben a la lírica erótica (Lecciones de Cupido - Lekcje Kupidynowe) (1617), pero aquellos textos recibieron tan duras críticas por parte de la censura eclesiástica que, unidas a una grave enfermedad que a punto estuvo de costarle la vida, le hicieron reflexionar y, finalmente, influyeron en su transformación espiritual, hasta el punto de convertirse en un poeta profundamente religioso. Twardowski, conocedor de la poesía mística española, introdujo en la poesía polaca la simbología y el mundo alegórico propios de ésta, y en los que los diferentes paisajes del jardín místico representan los diferentes estados del alma del caminante: Barca de la juventud que navega desde la tormenta hacia la orilla (É́dź młodzi z nawatności do brzegu płynaca) (1618) y Antorcha del amor divino con cinco flechas de fuego (Pochodnia miłości Bożej z pięcioma ognistymi strzałami) (1628).

En el terreno de la poesía, otro ejemplo evidente de huellas españolas lo encontramos en los poemas de Jan Andrzej Morsztyn (1613 ó 1621-1693), titulados «A una yegua española» («Na klacz hiszpańską»), «Baño» («Łaźnia»), «Inconstancia» («Niestatek», «Escapó el ruiseñor» «Stowik zbiegt» $\mathrm{y}$ «A una doncella» («Do panny»), en los que son muchos los autores que ven algo más que ecos de los sonetos de Lope de Vega, así como en su traducción al polaco de El Cid (Le Cid) (1636) de Pierre Corneille (1606-1684), realizada hacia 1660 y a la que dio el título polaco El Cid o Rodrigo, comedia española (Cid albo Roderik, komedia hiszpańska).

También resulta más que probable que la canción popular de tradición oral y tema laico del siglo XVII Caza de Cupido (Myślistwo kupidynowe) hubiera tenido como modelo el texto religioso, deudor de la poesía mística española, Caza del espíritu de Jesucristo (Myślistwo duchowego Jezusa Chrystusa).

Al menos dos comedias de inspiración española salieron de la pluma de Stanisław Herakliusz Lubomirski, el autor que con mayor ahínco intentó crear una comedia nacional polaca en el siglo XVII, poniendo en los escenarios palaciegos polacos el modelo de la comedia española e italiana. Se trata de Comedia del viejo Lopes con Spirydion (Komedyja Lopesa starego ze Spirydonem) y Don Alvares o la compañía indómita en el amor (Don Alvares albo Niesforna w miłości kompanija), basadas ambas 
en la novelas de Boccaccio. La primera, Lopes, trata del conflicto matrimonial entre el viejo doctor Lopes y la joven y bella Melisa, hija de uno de sus amigos. Lopes, con la intención de salvar su matrimonio, elabora un calendario relativo a las fechas de abstinencia de las relaciones matrimoniales, pero ocurre que en dicho calendario la cantidad de tales días es mayor que los que el año realmente tiene. Las protestas de Melisa no se hacen esperar y, no convencida por las explicaciones de su marido, resuelve, ya en la misma noche de bodas, encontrarse con un joven llamado Spirydon mientras aquél contempla los planetas. En la segunda comedia, Don Alvares, nos presenta a Don Gusman de Toledo, quien, a causa de la guerra de los españoles con los árabes, tiene que separarse de su esposa, Antonija. La falsa noticia de la muerte de Gusman es aprovechada por Don Alvares para intentar seducir a la supuesta viuda, quien, milagrosamente, no llega a rendirse a Don Alvares. En general, se trata de obras de que no presentan una gran teatralidad. A pesar de los numerosos motivos exóticos, la variedad de acción (63 escenas en Don Alvares y 36 en Lopes) y el amplio repertorio de personajes, estas comedias carecen de naturalidad teatral y de un lenguaje propio, el cual Lubomirski intenta imitar según los modelos de las comedias españolas e italianas, conocidas en profundidad por él durante sus estancias en España e Italia.

Durante la segunda mitad del siglo XVII tiene lugar un notable retroceso en el desarrollo de las relaciones hispano-polacas, lo que influye en el campo de la recepción de la literatura española en Polonia. En el terreno político, al decaimiento de la hegemonía española en el mundo, lo que desencadenó una pérdida de interés generalizada por «lo español», se unió el debilitamiento político y económico de Polonia en Europa Central a causa de las constantes guerras con Rusia, Suecia y Turquía. Además, el desarrollo ideológico de las ideas del 'sarmatismo', alentadas por el espíritu de la Contrarreforma, dieron lugar a un relativo aislamiento de Polonia en el marco europeo. La teoría del origen sármata de los polacos ya se apuntaba en las crónicas del siglo XVI, sobre todo de Maciej de Miechów (1457-1523) (Chronica Polonorum) (1519), Aleksander Gwagnin (1534-1614) (Sarmatiae europeae descriptio) (1578) y Stanislaw Sarnicki (h.1532-1597) (Annales, sive de origene et rebus gestis polonorum et lituanorum libri octo (1587), aunque es en el XVII cuando adquiere verdadera relevancia. Estas obras, aunque de diferente carácter, determinaron decisivamente el concepto de «nación polaca», limitado exclusivamente a la nobleza, y cuyas raíces se hallan en la antigua nación de los sármatas. Esto trajo el pleno convencimiento de que el valor del hombre depende de la antigüedad de su linaje, lo que a su vez desembocó en un aumento del culto a la tradición y una relativa pérdida de interés por lo proveniente del fuera de las fronteras polacas. La llegada a Polonia del poeta y literato alemán Martin Opitz (1597-1639), que huía de los Habsburgo, alimentó notablemente la formación de una teoría del sarmatismo. Esta fue aceptada con agrado por la nobleza polaca, que comenzó a asumir la idea de una Polonia concebida por Dios como el 'pueblo elegido' para defender la Cristiandad en la nueva era. Consecuencia de ello fue el aumento de la intolerancia religiosa y de pensamiento, algo que, por otro lado, era habitual durante en este siglo en el que triunfan en Europa las monarquías absolutistas. Al enfriamiento de las relaciones hispano-polacas a partir de mediados del siglo XVII seguirá su intenso restablecimiento a principios del siglo XIX, en el que se inicia una nueva etapa de 
intensas relaciones culturales, literarias y políticas, prácticamente ininterrumpidas hasta la época actual.

\section{Bibliografía}

BorowsKI, A. (2005): «Motywy karmelitańskie w literaturze polskiej», Cztery wieki Karmelitów Bosych w Polsce (1605-2005), Andrzej RuszaŁA, ed., Wydawnictwo Karmelitów Bosych, Cracovia, pp. 245-260.

Bustos Tovar, E. (1973): «La introducción de las teorías de Copérnico en la Universidad de Salamanca», Revista de la Academia de Ciencias Exactas, Físicas y Naturales, LXVII, 2.

CzYŻ, A. (1988): Ja i Bóg. Poezja metafizyczna późnego baroku, Studia staropolskie, vol. 54, Zakład Narodowy im. Ossolińskich, Wrocław.

FONTÁN, A., AXER, J. (1994): Españoles y polacos en la Corte de Carlos V. Madrid, Alianza Editorial. García Hernán, E., Skowron, R. (2015), From Ireland to Poland (Northern Europe, Spain and the Early Modern World). Valencia, Albatros.

GóRski, K. (2009): Pisarze ascetyczno-mistyczni Polski, t. 1, Uniwersytet im. Adama Mickiewicza, Wydział Teologiczny, Redakcja Wydawnictw, Poznań.

KACZOR-SCHEITER, K. (2005): Mistycyzm hiszpański w piśmiennictwie polskich karmelitanek XVII $i$ XVIII wieki. Archidiecezjalne Wydawnictwo Łódzkie, Łódz.

KrasiŃSKI, Zygmunt (2009), La no Divina Comedia, edición y traducción de Fernando Presa González. Madrid, Cátedra, Letras Universales, n. 415.

MakowieckA, G. (1984): Po drogach polsko-hiszpańskich. Wydawnictwo Literackie, Cracovia.

OdRIOZOla, A. (1982): Estanislao Polono. Un extraordinario impresor polaco en la España de los siglos XV y XVI (1491-1504). Diputación Provincial de Pontevedra.

PiOtrowski, B., BAYÓN, G. (1979): «La Colección Volsciana de Cracovia: Una biblioteca con antiguos textos españoles en la Universidad de Cracovia», Tiempo de Historia, año VI, n. 61, pp. $120-124$.

PopŁAwsKa, H. (1995): «Autobiografia mistyczna», Czesław Hernas, Mirosław Hanusiewicz (eds.), Religijność literatury polskiego baroku. Lublin, pp. 101-123.

SAJKowsKi, A. (1979): «Droga do Compostelli albo sto lat podróży Polaków do Hiszpanii», Filologia Polska, XVI, Torun. 